\title{
Social Computing in Corporations
}

\author{
Social Computing in Unternehmen
}

Michael Koch, Bundeswehr University Munich

Social computing refers to supporting social interaction and socialization by the use of IT systems [1;2]. Within that context, the term "social software" is used for tools or services that "support, extend or derive added value from human social behavior" [3]. While both terms "social computing" and "social software" have only become relatively popular within the last five years, the core ideas behind them have a much longer history, going back to Vannevar Bush's ideas about the Memex in 1945 [4], and traveling through terms such as Groupware and computer-supported collaborative work (CSCW) in the 1970 s to 1990s. A very good documentation tracing this evolution can be found in a blog post by Christopher Allen [5].

One of the most important concepts in social computing is participation, which means the free cooperation of as many people as possible without any restrictions of organizations, processes, technologies or particular platforms.

The straightforward possibility for everyone to participate and contribute to the big picture can enrich existing classic knowledge management approaches in organizations. Since knowledge, know-how, and qualifications of employees are crucial resources, it bears enormous potential to facilitate their participation [6].

In this context, the term "Enterprise 2.0" has been coined by Andrew McAfee for using social software to support collaborative work and knowledge management "within a company or between companies and their partners or customers" [7].

For in-company operation, social software is typically adjusted to the company context, and integrated with existing intra-company tools [8-10]. Since cooperation is not limited to individual organizations, social software is also employed for facilitating communication with customers and business partners. As long as this results in a bi-directional communication, it is seen as part of Enterprise 2.0. If social software is just used for communicating uni-directionally from the company to customers, it usually is not in the scope of Enterprise 2.0.
Some interpretations of the term "Enterprise 2.0" even go beyond the tool level, and focus on the structural changes in companies enabled by the introduction of social software. Keywords in this context are "easier, faster, and contextual organization of access to information, expertise, and business contacts" [11].

One very important characteristic of social software is its openness to individual use because of its missing specialization to particular usage scenarios. This media feature of social software or Groupware [12] is called "Nutzungsoffenheit" (open usage) in current publications (e.g. [13]). In this aspect, social software differs strikingly from traditional business software such as ERP, CRM, or PPC systems, which have clear structures, processes and pre-defined underlying use cases already during their development.

A very nice example for adapting a service in a new way can be found in the beginnings of the Internet. The network initially only included remote login and file transfer services. The file transfer service soon was "misused" by the users to exchange messages - email was invented [14].

In this special issue we have brought together six articles covering different aspects of social computing in corporations.

The article "A review of microblogging in the enterprise" by Stocker et al. addresses microblogs as one particular type of social software. Since the core feature of microblogs, the support of mutual awareness by activity streams, has become one of the most important technical features of all social computing platforms, a deeper analysis of microblogging contributes to understanding the whole field.

In "Implementation of collaborative software in enterprises: a thematic analysis", Schubert and Williams review sixteen successful cases of social software in organizations in order to identify structures, processes and activities associated with the implementation of such solutions. The identified issues are presented using the $8 \mathrm{C}$ Framework showing different potential implications for the introduction of social software. 
The article "Implementing a classification scheme for Enterprise 2.0" by Back and Irmler presents a classification scheme for structuring the subject area, particularly for describing specific solutions in detail. The classification scheme includes thirteen categories and was implemented to support search in the Enterprise 2.0 case study database e20cases.org.

As stated earlier, the history of supporting social interaction goes back quite a while, involving the important area of Groupware. In "From Groupware to social mediaextending an existing shared workplace system with social media features", Prinz and Kolvenbach take a "classic" Groupware tool, the BSCW shared workspace, and analyze what has to be added to make this software more "social". They identify ways for the evolution of a cooperation platform into a social media platform.

The article "The connected company - bridging data silos" by Schmaltz and Aziz contrasts "systems of record" (the classic business software) from "systems of engagement" (social software). They present challenges and solutions for the integration of both.

Finally, the article "Social software beyond the Desktopambient awareness and ubiquitous activity streaming" by Ott and me extends the scope of social software beyond today's desktops and mobile devices. It takes up the core feature of activity streams mentioned before and presents a concept for additional ubiquitous natural user interfaces. Large touchscreens can help to leverage the full socio-technical potential of social software in semi-public "social" spaces, like e.g., coffee corners.

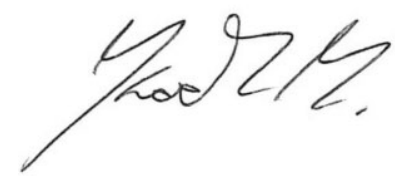

Prof. Dr. Michael Koch

\section{References}

[1] D. Schuler, "Social Computing", Communications of the ACM, vol. 37, no. 1, pp. 28-29, 1994.

[2] F.-Y. Wang, D. Zeng, K. M. Carley, and W. Mao, "Social Computing: From Social Informatics to Social Intelligence", IEEE Intelligent Systems, vol. 22, no. 2, pp. 79-83, 2007.
[3] T. Coates, "An addendum to a definition of Social Software", 2005. [Online]. Available: http://www.plasticbag.org/archives/2005/01/ an_addendum_to_a_definition_of_social_software/. [Accessed: 01-Oct-2010].

[4] V. Busch, "As we may think. A top U. S. scientists forsees a possible future world in which man-made machines will start to think", Life Magazine, vol. 19, pp. 112-124, 1945.

[5] C. Allen, "Tracing the Evolution of Social Software", 2004. [Online]. Available: http://www.lifewithalacrity.com/2004/10/tracing the_evo.html.

[6] A. Back and M. Koch, "Broadening Participation in Knowledge Management in Enterprise 2.0", it - Information Technology, vol. 53, no. 3, pp. 135-141, 2011.

[7] A. McAfee, "Enterprise 2.0: The dawn of emergent collaboration", MIT Sloan management review, vol. 47, no. 3, p. 21, 2006

[8] W. Buhse and S. Stamer, Eds., Enterprise 2.0 - The Art of Letting Go. New York, NY: iUniverse, 2008.

[9] A. Back, N. Gronau, and K. Tochtermann, Eds., Web 2.0 in der Unternehmenspraxis - Grundlagen, Fallstudien und Trends zum Einsatz von Social Software. München: Oldenbourg Wissenschaftsverlag, 2009.

[10] M. Koch and A. Richter, Enterprise 2.0 - Planung, Einführung und erfolgreicher Einsatz von Social Software in Unternehmen. München: Oldenbourg Wissenschaftsverlag, 2009.

[11] J. N. Hoover, "Most Business Tech Pros Wary About Web 2.0 Tools In Business", InformationWeek, no. 24.02.2007, 2007.

[12] M. Koch, "CSCW and Enterprise 2.0 - towards an integrated perspective", in Proc. Conf. Bled eConference eCollaboration, 2008, pp. 416-427.

[13] A. Richter, S. Behrendt, and M. Koch, "APERTO: A Framework for Selection, Introduction, and Optimization of Corporate Social Software", Sprouts: Working Papers on Information Systems, vol. 12, no. 1, pp. 1-22, 2012.

[14] K. Hafner and M. Lyon, Where Wizards Stay Up Late: The Origins of the Internet. New York, NY: Simon \& Schuster, 1996.

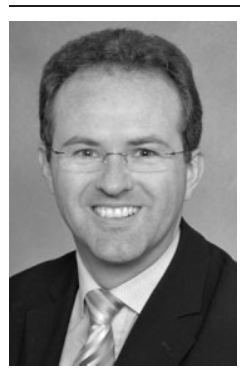

Prof. Dr. Michael Koch is full professor for applied informatics at Bundeswehr University $\mathrm{Mu}$ nich where he is leading the Cooperation Systems Center Munich (CSCM). His work is about shaping cooperation systems, i. e. bringing collaboration technology to use in teams, communities and networks. He is member of the boards of the special interest groups on Human Computer Interaction and Information Systems in the Gesellschaft für Informatik (GI).

Address: Universität der Bundeswehr München, Fakultät für Informatik, Werner-Heisenberg-Weg 39, D-85577 Neubiberg, e-mail: michael.koch@unibw.de 